Michael J. Smith · J. Dale Roberts

\title{
An experimental examination of female preference patterns for components of the male advertisement call in the quacking frog, Crinia georgiana
}

Published online: 16 January 2004

(C) Springer-Verlag 2004

\section{Behav Ecol Sociobiol (2003) 55:144-150}

The above article was communicated by T. Czeschlik

The online version of the original article can be found at http://dx.doi.org/10.1007/s00265-003-0691-3

M. J. Smith $(\varangle)$ J J. D. Roberts

Department of Zoology,

University of Western Australia,

35 Stirling Highway Crawley, Perth, Western Australia 6009,

Australia

e-mail: smithmicha@missouri.edu

Tel.: +1-573-8847883

Present address:

M. J. Smith, Division of Biological Sciences,

University of Missouri,

Columbia, Missouri 65211, USA 